\title{
Selection of laser processing parameters for hot stamping tools based on mathematical planning of the experiment
}

\author{
N. A. Chichenev, Dr. Eng., Prof., Dept. of Engineering of Technological Equipment ${ }^{1}$,e-mail: chich38@mail.ru \\ O. N. Chicheneva, Cand. Eng., Associate Prof. ${ }^{1}$, e-mail: ch-grafika@mail.ru \\ A. O. Karfidov, Head of Dept. of Engineering of Technological Equipment ${ }^{1}$, e-mail: a.korf@mail.ru \\ A. N. Pashkov, Cand. Eng., Associate Prof., Dept. of Engineering of Technological Equipment, Deputy Head of the RPC \\ for Scientific work of "NPP "Istok" named after A. I. Shokin', e-mail: a.n.pashkov@yandex.ru
}

${ }^{1}$ National University of Science and Technology “MISiS”, Moscow, Russia

\begin{abstract}
The results of experimental studies to determine the influence of the technological parameters of laser processing of $3 \mathrm{Kh} 3 \mathrm{M} 3 \mathrm{~F}$ die steel on the service life of the working tool of a hot-stamping machine designed for hot stamping of rolling bearing rings are presented. Development of a mathematical model of the tool's resistance to laser radiation parameters was carried out by the method of mathematical planning of the experiment using a full factorial experiment. Durability of the die tool N (in thousand forgings) was chosen as an optimization criterion, while dimensionless (generalized) parameters of the speed $V^{*}$ and power $P^{*}$ of laser processing, as well as the overlap coefficient of laser tracks $S^{*}$ were proposed to use as factors. The obtained mathematical model of the resistance of laser-hardened die tools for hot deformation is used for the development and optimization of laser quenching modes without melting the surface of the ejectors in order to increase their thermal fatigue strength. Due to the fact that dimensionless factors containing the thermophysical characteristics of the die tool material are used in the planning of the experiment, the developed mathematical model can be used to assess the operational resistance of other heat-resistant tool steels of the martensite class.
\end{abstract}

Key words: die steels for hot stamping; thermal fatigue, laser quenching, mathematical planning of the experiment, dimensionless parameters.

DOI: $10.17580 /$ cisisr.2021.02.07

\section{Introduction}

Various methods of hot stamping are widely used in different industrial branches, what is stipulated by their high technical and economical parameters, such as high productivity, side variety of stampings, low cost etc. [1, 2]. Stamping tools for hot deformation operate in very complicated industrial conditions (high temperature, large contact stresses, cyclic loads etc.), thereby increased operating resistance requirements are formulated for these tools. It is caused by the reason that its stable and reliable operation mainly determines productivity of stamping equipment, yield and quality of finished products [3, 4].

Thermomechanical features of tool loading in hot stamping leads to appearance of erosion, which is based on die metal fatigue stipulated on volumetric variation of surface layers in the conditions of constrained deformation. It finalizes, in its turn, in forming the areas of local plastic deformation and arising of thermal fatigue cracks.

Different methods for increase of metal thermal fatigue strength are applied for elevation of durability of hot stamping tool which is susceptible to erosion [5, 6]. At present time, owing to intensice scientific and technical development, laser heat treatment is used for surface hardening of the components and tools of different purposes, i.e. for working surfaces of technological metal forming tools [7-10]. At the same time, the problems of laser thermal hardening of $3 \mathrm{Kh} 3 \mathrm{M} 3 \mathrm{~F}$ die steel are observed insufficiently for development of laser processing technological procedures. This steel is widely used for manufacture of deformation tools operating at increased temperature. Some investigations examined the problems of laser quenching of $3 \mathrm{Kh} 3 \mathrm{M} 3 \mathrm{~F}$ die steel with surface melting, what can lead sometimes to unacceptable deterioration of surface morphology.

\section{Aim of the work}

This article observes experimental investigation of influence of technological parameters of laser processing of $3 \mathrm{Kh} 3 \mathrm{M} 3 \mathrm{~F}$ die steel on operating resistance of working tool of hot-stamping machines, which are designed for hot stamping of roll bearing rings. Thereby development and optimization of laser quenching modes without surface melting on ejectors, in order to rise thermal fatigue strength of these roll bearing rings, are the aims of this research.

\section{Research, its results and analysis}

Development of the mathematical model of tool resistance from the effect of laser radiation was conducted via the method of mathematical planning of the experiment, using a full factorial experiment [11]. It was carried out in such way due to insufficient theoretical background of the problems of interaction between laser radiation and tool steels.

Ejectors were taken as the subject of this research as the elements of die auxiliaries, which are most susceptible for wear. These ejectors are located in hot-stamping machines for hot stamping of roll bearing rings made of $3 \mathrm{Kh} 3 \mathrm{M} 3 \mathrm{~F}$ die 
steel with the following thermophysical properties: melting temperature $T_{\mathrm{mel}}=1560^{\circ} \mathrm{C}$; temperature conductivity coefficient $a=0.075 \mathrm{~cm}^{2} / \mathrm{s}$; heat conductivity coefficient $\lambda=0.34 \mathrm{Wt} /(\mathrm{cm} \cdot \mathrm{grad})$.

The following main parameters have influence on operating properties of laser hardened steels: power of laser emission $P$, diameter of laser spot $d_{\mathrm{s}}$, speed of laser ray transmission along the processing surface $V$, mutual location and route of laser tracks application.

To assess the effect of the route of laser tracks location, the special experiment was carried out. It included application of laser tracks as parallel lines, concentric peripheries and spirals on the working surfaces of ejectors (Fig. 1).

The experiments displayed, that substantial difference in resistance of ejectors, which were processed via different routes, was not revealed. Thereby the route of application of laser tracks as concentric peripheries was accepts as the most technically simple and providing larger productivity.

Durability of the die tool $N$ (in thousand forgings) was chosen as an optimization criterion, while dimensionless (generalized) parameters of the speed $V^{*}$ and power $P^{*}$ of laser processing, as well as the overlap coefficient of laser tracks $S^{*}$, which were determined via the following formulas [12], were proposed to use as factors.

$$
V^{*}=\frac{V \cdot d_{s}}{4 \cdot a}, \quad P^{*}=\frac{T_{m e l} \cdot d_{s} \cdot \lambda}{2 \cdot K_{a b s} \cdot P}, \quad s^{*}=\frac{s}{d_{s}},
$$

where $T_{\text {mel }}$ - melting temperature, ${ }^{\circ} \mathrm{C}$;

$a$ - temperature conductivity coefficient, $\mathrm{cm}^{2} / \mathrm{s}$;

$\lambda$ - heat conductivity coefficient, $\mathrm{Wt} /(\mathrm{cm} \cdot \mathrm{grad})$;

$d_{\mathrm{s}}-$ diameter of laser spot, $\mathrm{cm}$;

$V$ - speed of laser ray transmission along the processing surface, $\mathrm{cm} / \mathrm{s}$;

$P$ - power of laser emission, Wt;

$s-$ step of laser tracks, $\mathrm{cm}$;

$K_{\text {abs }}$ - absorption coefficient.

Variation areas of the absolute values of parameters, which are presented in the above-mentioned expressions, were chosen on the base of literature data and results of preliminary experiment conducted with the samples of 3Kh3M3F steel:

$$
\begin{gathered}
P=1,5 \ldots 2,5 \mathrm{kWt} ; V=0,5 \ldots 1,0 \mathrm{~cm} / \mathrm{s} ; d_{\mathrm{s}}=0,5 \ldots 1,0 \mathrm{~cm} ; \\
s=(0,8 \ldots 1,6) \cdot d_{\mathrm{s}}=0,4 \ldots 1,6 \mathrm{~cm} ; K_{\mathrm{abs}}=0,8 .
\end{gathered}
$$

Taking into account these values and thermophysical characteristics of $3 \mathrm{Kh} 3 \mathrm{M} 3 \mathrm{~F}$ steel, the following variation ranges for the factors were obtained:

$$
P^{*}=0,066 \ldots 0,220 ; \quad V^{*}=0,83 \ldots 3,33 ; \quad s^{*}=0,8 \ldots 1,6 .
$$

The response function was presented as a second degree polynom and orthogonal composite central plan of the second order, containing 17 points, was used for determination of its coefficients. After laser processing, the ejectors were placed in a die block of the hot-stamping machine for consequent tests in production conditions and fixation of their resistance. 5 repeated experiments were carried out in the each point of the experiment planning matrix. Thereby, 85 ejectors were tested to build the regression equation.

The following mathematical model of resistance of laser hardened die tool for hot deformation was obtained after checking of uniformity of dispersions (according to Cochrane criterion), after assessment of meaningfulness of regression coefficients (according to Student criterion) and evaluation of the model adequacy (according to Fisher criterion):

$$
\begin{aligned}
N= & 19,6+17,6 \cdot V^{*}-11,5 \cdot P^{*}+3,70 \cdot V^{*} \cdot P^{*}- \\
& -4,02 \cdot V^{* 2}-13,4 \cdot P^{* 2}-2,73 \cdot S^{* 2} .
\end{aligned}
$$

Analysis of the obtained relationship shows, that the response function achieves its maximal value $(N)_{\max }=49$ thousand stampings for the following factor values: $P^{*}=0,145$; $V^{*}=2,31 ; S^{*}=1,1$.

Taking into account smooth type of the response function near the extremal point and dispersion of the testing results, the following procedures of laser processing for die tool made of $3 \mathrm{Kh} 3 \mathrm{M} 3 \mathrm{~F}$ steel are recommended:

$$
P^{*}=0,13 \ldots 0,16 ; V^{*}=2,1 \ldots 2,5 ; S^{*}=1,0 \ldots 1,2 .
$$

As soon as dimensionless factors including thermophysical material characteristics of die tools were used during experiment planning, the developed mathematical model can be used for assessment of operating resistance of also other heat-resistant tool steels of martensite class.

It was established as a result of metallographic examination of the area of laser effect and its wear kinetics, that increase of ejectors' resistance is connected first of all with the properties and structural peculiarities of melted zone after quenching. Dendrite microstructure is typical for the

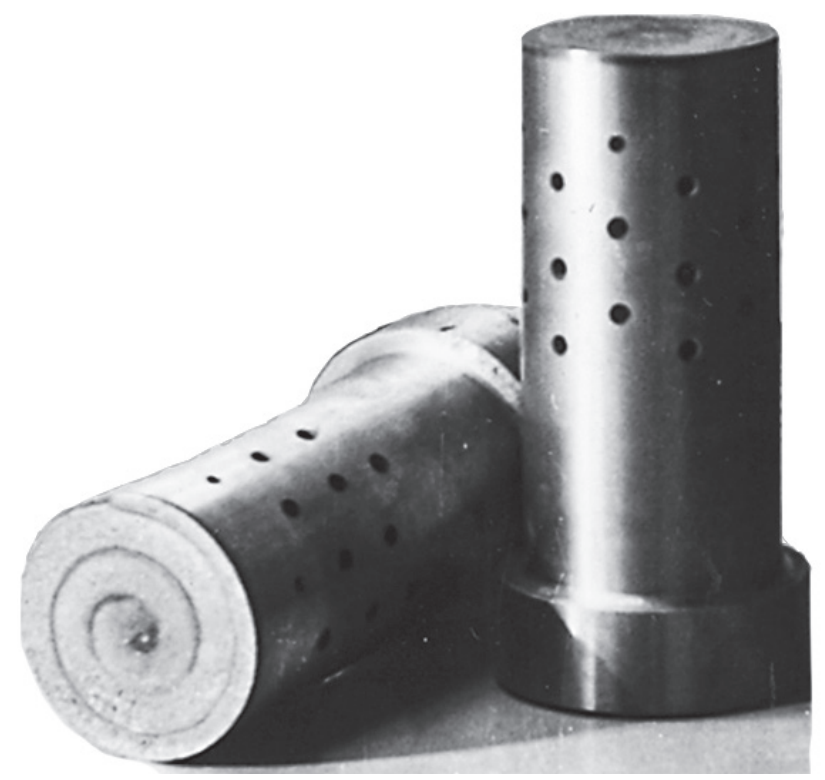

Fig. 1. Ejectors with laser tracks, applied on the working surface as a spiral (left) and concentric tracks (right) 
melting zone, and structure dispersity is higher by 3 times in average in comparison with usual quenching. Microhardness of molten layer with thickness 3-4 mm exceeds steel hardness in initial state by 3,000-5,500 $\mathrm{MPa}$ (depending on laser processing procedure). Phase analysis displayed that molten zone consists of martensite and austenite, while carbides of alloying elements are practically absent, what allows to make conclusion about their complete dissolution during laser quenching. Content of residual austenite makes 7-15\%, depending on laser processing procedure.

Depth of laser quenching zone (melting and quenching) and parameters of its durability can't be increased unlimitedly with density enlargement of emission power $q=4 \cdot \mathrm{P} /\left(\pi \cdot d_{\mathrm{s}}^{2}\right)$. When $q>5-7 \mathrm{kWt} / \mathrm{cm}^{2}, 3 \mathrm{Kh} 3 \mathrm{M} 3 \mathrm{~F}$ steel is heated essentially higher than melting temperature, what causes rise of austenite alloying and decrease of martensite interval and, consequently, structure with substantial amount of residual austenite $(>20 \%)$ is formed. Microhardness of such quenched layer is essentially lower, than that of layer with martensite structure, where amount of residual austenite makes $<7 \%$. However, the problem of hot stamping tool resistance increase includes also elimination of surface defects. That's why the suggested laser heat treatment procedure for die steel $3 \mathrm{Kh} 3 \mathrm{M} 3 \mathrm{~F}$ corresponds to such melting, when the amount of residual austenite after laser processing makes $10-11 \%$.

Analysis of thermal fatigue destruction of laser hardened layers showed that the uniform fine-dispersed zone of melting (which has no structural defects - pores, inclusions) and adjacent zone of quenching from solid phase are characterized by increased resistance to thermal fatigue crack forming.

Laser processing of hot stamping tools was carried out by continuous $\mathrm{CO}_{2}$ laser. Setting of the required size and form of laser spot on the processing surface was conducted by focusing of laser beam, using optical lens and scanning device tuning $[13,14]$.

The tool after preliminary volumetric heat treatment according to the standard technology and grinding was also subjected to laser processing. Cleaning of the die working surface, application of light absorbing coating and its drying were conducted just before laser hardening treatment. Die tool after such laser hardening processing by the developed technology does not require consequent mechanical processing and is ready for operation.

Pilot-industrial tests showed that use of laser processing provides increase of resistance of ejectors of different types by 2-3 times; laser processing of punches was accompanied by application of circular tracks on the working surface via punch rotation around its axis.

As soon as amount of thermal fatigue cracks in laser hardened tools decreased essentially in comparison with tools processed via conventional technology, likelihood of repeated use of worn die tools (ejectors and punches) was checked. Defect layer, which was determined by depth of propagation of erosion cracks, was removed mechanically from the surface of laser hardened worn ejectors (already shown three-fold resistance increase). After grinding, the working surfaces were processed by laser emission, preliminary volumetric treatment is not required in this case, and ejectors were used again in operation.

It was established as a result of testing, that resistance of ejectors after their repeated processing by laser emission exceeds resistance of new tool (which was subjected to volumetric heat treatment according to the plant technology) by two times. It is shown that such operation can be conducted from 2 to 4 times.

\section{Conclusions}

The results of experimental researches on influence of technological parameters of laser processing for die steel $3 \mathrm{Kh} 3 \mathrm{M} 3 \mathrm{~F}$ on operating resistance of working tool of hotstamping machine for hot stamping of roll bearing rings are presented. Development of mathematical model of tool resistance on laser emission parameters was carried out via the method of mathematical planning of the experiment using full factorial experiment.

Durability of the die tool $N$ (in thousand forgings) was chosen as an optimization criterion, while dimensionless (generalized) parameters of the speed $V^{*}$ and power $P^{*}$ of laser processing, as well as the overlap coefficient of laser tracks $S^{*}$ were proposed to use as factors. The obtained mathematical model of resistance of laser-hardened die tool for hot deformation was used for development and optimization of laser quenching procedures without melting of surfaces of ejectors, in order to increase their thermal fatigue strength.

\section{Prospects of further researches in this field}

As soon as dimensionless factors, containing thermophysical characteristics of die tool material, were used during planning of the experiment, the developed mathematical model can be applied for assessment of operating resistance also of other heat-resistant steels of martensite class [15-18].

\section{REFERENCES}

1. Konstantinov I. L. Technology of forging and hot volumetric stamping. A manual. Moscow: NITs INFRA-M. 2019. 104 p.

2. Semenov E. I. Forging and hot stamping. A manual. Moscow. MGIU. 2011. 414 p.

3. Stenico A., Tami W. Experience of improvement of direct quenching technology at the plant in the USA. Chernye metally. 2018. No. 12. pp. 41-43.

4. Vasilyev D. I., Tylkin M. A., Teterin G. P. Designing grounds for deformation tools. Moscow: Vysshaya shkola. 1980. 223 p.

5. Gorbatyuk S. M., Pashkov A. N., Morozova I. G., Chicheneva O. N. Technologies for applying Ni-Au coatings to heat sinks of SiC-Al metal matrix composite material. Materials Today: Proceedings. 2021. Vol. 38. pp. 1889-1893. DOI: 10.1016/j.matpr.2020.08.581.

6. Smirnov A. E. Managing phase composition of complex alloyed heat-resistant steels during vacuum cementation and quenching. Metallovedenie i termicheskaya obrabotka metallov. 2020. Vol. 783. No. 9. pp. 45-52.

7. Maharjan N., Zhou W., Zhou Y., Wu, N. Underwater laser hardening of bearing steels. Journal of Manufacturing Processes. 2019. Vol. 47. pp. 52-61. DOI: 10.1016/j.jmapro.2019.08.020. 
8. Khorram A., Davoodi Jamaloei A., Jafari A., Moradi M. Nd:YAG laser surface hardening of AISI 431 stainless steel; mechanical and metallurgical investigation. Optics and Laser Technology. 2019. Vol. 119. Article No 105617. DOI: 10.1016/j.optlastec.2019.105617.

9. Bahrami Balajaddeh M., Naffakh Moosavy H. Pulsed Nd:YAG laser welding of 17-4 PH stainless steel: Microstructure, mechanical properties, and weldability investigation. Optics and Laser Technology. 2019. Vol. 119. Article No 105651. DOI: 10.1016/j. optlastec.2019.105651.

10. Gornyi S.G., Grechko Yu. B., Patrov M.I., Yudin K.V., Yurevich V.I. Laser marking of materials. Fotonika. 2007. No. 3. pp. 16-22.

11. Makarichev Yu. A., Ivannikov Yu. N. Methods of experiment planning and data processing. A manual. Samara: Samarskiy gosudarstvennyi tekhnicheskiy universitet. 2016. $131 \mathrm{p}$.

12. Chichenev N.A., Gorbatyuk S. M., Naumova M.G.; Morozova I. G. Using the similarity theory to describe laser hardening processes. CIS Iron and Steel Review. 2020. Vol. 19. pp. 44-47.

13. Grigoryants A. G., Shiganov I. N., Misyurov A. I. Technological processes of paser treatment. A manual. Moscow: Izdatelstvo MGTU im. N. E. Baumana. 2006. 663 p.
14. Laser technologies of materials processing: up-to-date problems of fundamental researches and applied developments. Edited by Panchenko V. Ya. Moscow: FIZMATLIT. 2009. 664 p.

15. Pinakhin I. A., Chernigovskiy V. A. Grounds of volumetric laser hardening of tool and structural materials. A monograph. Stavropol. Izdatelstvo SKFU. 2014. 160 p.

16. Nefedov A. V., Svichkar V. V., Chicheneva O. N. Re-engineering of Equipment to Feed the Melting Furnace with Aluminum Charge. Lecture Notes in Mechanical Engineering. 2021. pp. 1198-1204. DOI: 10.1007/978-3-030-54817-9_139.

17. Aborkin A. V., Vaganov V. E., Shlegel A. N., Bukarev I. M. Effect of laser hardening on die steel micro hardness and surface quality. Metallurgist. 2015. Vol. 59. No. 7-8. pp. 619-625.

18. Nefedov A. V., Novikova Yu. V., Chicheneva O. N. Manipulator for feeding a box with liquid solution for repair of cast iron buckets at blast furnace shop of JSC "Ural Steel”. Chernye Metally, 2021. No. 8. pp. 4-9. DOI: 10.17580/chm.2021.08.01. 